\title{
MECHANICAL PROPERTIES OF STEEL FIBRE REINFORCED CONCRETE
}

\author{
KABIRU SALIHU \& ISA MALLUM
}

Research Scholar, Department of Civil Engineering, College of Engineering Technology, Yola. Adamawa State Polytechnic,

Yola. Adamawa, Nigeria

\begin{abstract}
Concrete is a composite material that is weak in tension and brittle under stresses and impacts load, thus, it cannot support the tensile load and stresses that come from beams and slabs appropriately. Previous studies show that the addition of steel fiber can considerably improve the tensile properties of concrete and the deformation characteristics of the composite. The mechanical properties of concrete containing steel fiber were investigated for M35 concrete grade. The results indicate a slight increment of about $15 \%$ compressive strength and $30 \%$ splitting tensile strength of the reinforced concrete compared to normal concrete. In general, the concrete containing steel fiber displays a substantial increase greater than $100 \%$ at 28 days when compared to normal concrete. The study, therefore, concludes that there is a significant improvement in the flexural strength of steel fiber reinforced concrete.

KEYWORDS: Mechanical Properties, Reinforced Concrete \& Steel Fibre
\end{abstract}

Received: Nov 11, 2019; Accepted: Dec 02, 2019; Published: May 09, 2020; Paper Id.: IJCSEIERDJUN202002

\section{INTRODUCTION}

Concrete is a broadly utilized material for building development for quite a long time which is feeble in strain and fragile in nature [1]. Normal concrete has low tensile properties; this effect limits its wider application in the engineering field [2]. Fiber-Reinforced Concrete (FRC) is a composite material composed of concrete matrix and fibers. The advantage of adding fibers to concrete is to increase the strength and durability of the concrete matrix [3]. According to previous studies, it was proven that the addition of steel fiber in concrete can improve fatigue resistance, ductility, shock résistance, and crack arrest. Consequently, it can be useful in many engineering fields such as pavement, slabs, pipes, channels, and tunnels [4].

The use of steel fiber shows a significant improvement in deformation characteristic of the composite when incorporated in the concrete due to a surge in toughness and tensile strength properties thereby improving the crack resistance. Though, the improvement in the toughness of FRC depends on the mechanical and bonding properties of the fiber-matrix as well as the quantity and the distribution within the matrix of fiber [5]. The presence of steel fiber improves static and dynamic properties of concrete and also shows a beneficial effect in compressive strength, flexural strength, impact and fatigue strengths of concrete [6]. The design and analysis of structures containing Steel Fiber Reinforced Concrete (SFRC) rely upon mechanical parameters.

One of the important characteristics of steel fiber reinforced concrete is the rupture energy, which assists in describing the properties of concrete and in determining the design criteria for concrete structures with SFRC [7]. The properties of concrete containing steel fiber with a dissimilar grade of concrete had been investigated. Findings revealed that the flexural strength of SFRC is above $100 \%$ increment [8]. It was likewise gathered that there is a huge improvement in the properties of concrete containing steel fiber compared to a normal 
one, Similar studies showed the effect of length of steel fiber on the strength properties of SFRC is higher than the effect of coarse aggregate size [9] [10]. The result indicates a significant increase in tensile and flexural properties of steel fiber concrete compared to normal concrete [9]. On the other hand, it is additionally seen that steel fibers with bigger coarse aggregate and long steel fiber had a substantial enhancement in SFRC properties. The addition of steel fibre increases the tensile and flexural properties of concrete for about 30\% compared to conventional concrete as steel fibre content increase $[11]$.

The investigation of the mechanical properties of cement concrete made of fibers from the waste tire was carried out. The outcome shows that concrete containing recycled fiber from waste tire shows that compressive strength increases about 5-12\% compared to normal concrete while concrete containing steel fiber increases 17-20\% compared to normal concrete. The result of the indirect tensile strength of concrete for both concrete containing recycled steel fiber from the waste tire and industrial steel fiber demonstrated a beneficial effect on the concrete properties than the normal concrete [12].

The behavior of ultra-high performance concrete with various steel fiber on the pull-out and tensile strength has been observed to have better resistance, especially when twisted, hooked or half hooked steel fiber is used instead of straight steel fiber. Similar studies show that the use of hooked end steel fiber had higher bonding, compared to other types of steel fiber when they are inclined at 30 or $45^{\circ} \mathrm{C}$ [13].

$\mathrm{Xu}$ et al. [14] studies show that steel fiber had little effect on the compressive strength of concrete. Though, significant improvement was recorded on the split tensile and flexural strength. Equally, Venkat et al. [6] studies indicate better performance in the mechanical properties of concrete containing steel fiber up to $3 \%$. However, in a different study by Jin et al.[15], the results indicate that the mechanical properties of steel fiber reinforced ultra-high-strength concrete was enhanced. It was also discovered that steel fiber reinforced concrete has a good absorption capacity. Conversely, Yoo et al. [16] reveal that the ductile properties of concrete were enhanced due to the addition of steel fibers in concrete. Besides, the study inferred that $1 \%$ of steel fiber content gives optimum percentage replacement for maximum flexural strength.

Furthermore, the study of Gajjar et al.[17] discovered that the mechanical properties of the concrete containing steel fibers were improved. The results indicate a 10-20\% improvement in compressive strength compare to normal concrete, whereas, the tensile properties had shown 3 - $35 \%$ while flexural strength record about $12-40 \%$. The literature is unanimous on the importance of understanding the performance of concrete containing steel fiber. This paper investigates the mechanical properties of hook end industrial steel fiber concrete grade M35 and it has also presented the influence of such fibers in the strength properties of concrete.

\section{MATERIALS AND METHODS}

Cement: The cement used is ordinary Portland cement of specific gravity $2.94 \mathrm{~g} / \mathrm{cm} 3$ was used for the experiment. Figure 2 shows the sample of the cement whereas, table 1 shows the chemical properties. 


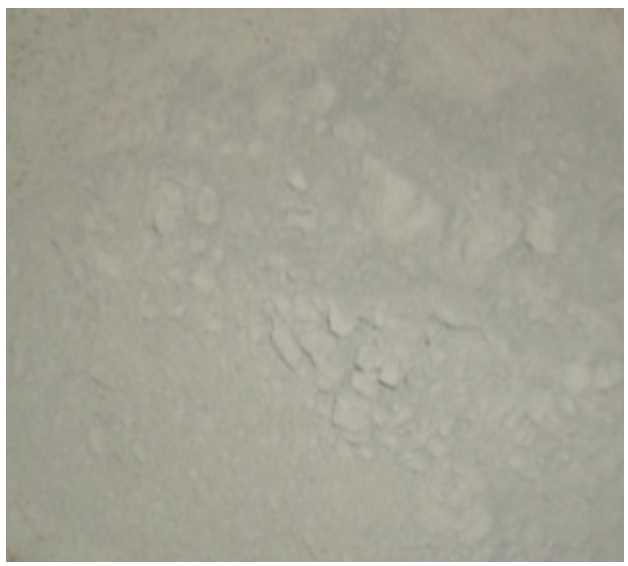

Figure 1: Portland Cement

Table 1: Chemical Properties of Cement

\begin{tabular}{|c|c|c|c|c|c|c|c|c|}
\hline $\mathrm{SiO}_{\mathbf{2}}$ & $\mathbf{F e}_{\mathbf{2}} \mathbf{O}_{\mathbf{3}}$ & $\mathbf{A l}_{2} \mathbf{O}_{\mathbf{3}}$ & $\mathbf{C a O}$ & $\mathbf{K}_{\mathbf{2}} \mathbf{O}$ & $\mathbf{M g O}$ & $\mathbf{N a}_{2} \mathbf{O}$ & $\mathbf{L O 1}$ & Specific Gravity (g/cm3) \\
\hline 21.03 & 2.58 & 6.16 & 64.47 & 0.61 & 2.62 & 0.34 & 1.73 & 2.94 \\
\hline
\end{tabular}

Aggregate (fine and coarse): The aggregate used for the experiment is $10 \mathrm{~mm}$ coarse aggregate and sand as fine aggregate. It was oven-dried to ensure no addition of water will alter the water-cement ratio in the process of the experiment.

Steel Fiber: Hook end steel fiber is used through-out the experiment to increase the tensile properties of concrete. One percent $(1 \%)$ steel fiber was used in the concrete grade M35. In another study, it was found that $1 \%$ of steel fiber gives maximum strength of the concrete grade M35[18]. Figure 3 shows a picture of the steel fiber type, whereas, in table 2, the properties of steel fiber were presented.

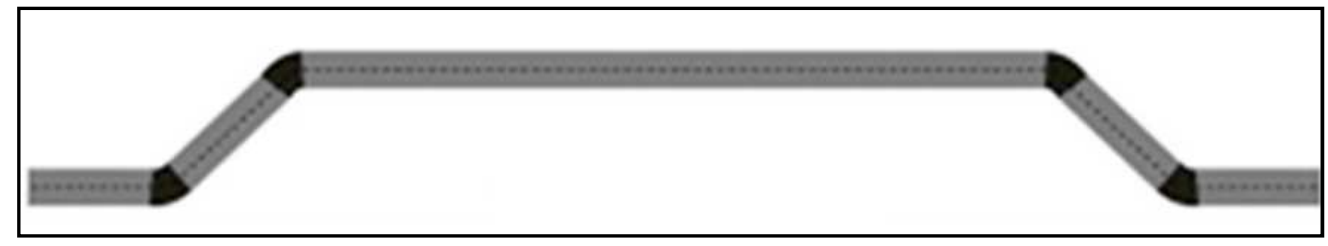

Figure 2: The Picture of Steel Fiber used

Table 2: Properties of Hook End Steel Fiber use for the Experiment

\begin{tabular}{|l|l|l|l|}
\hline $\begin{array}{c}\text { length } \\
(\mathbf{m m})\end{array}$ & $\begin{array}{c}\text { Diameter } \\
(\mathbf{m m})\end{array}$ & $\begin{array}{c}\text { Aspect ratio } \\
(\mathbf{l} / \mathbf{d})\end{array}$ & Shape \\
\hline 35 & 0.6 & 58 & Hook end \\
\hline
\end{tabular}


Figure 3 presents a flow chart summarizing the laboratory methods used in carrying out the experiment.

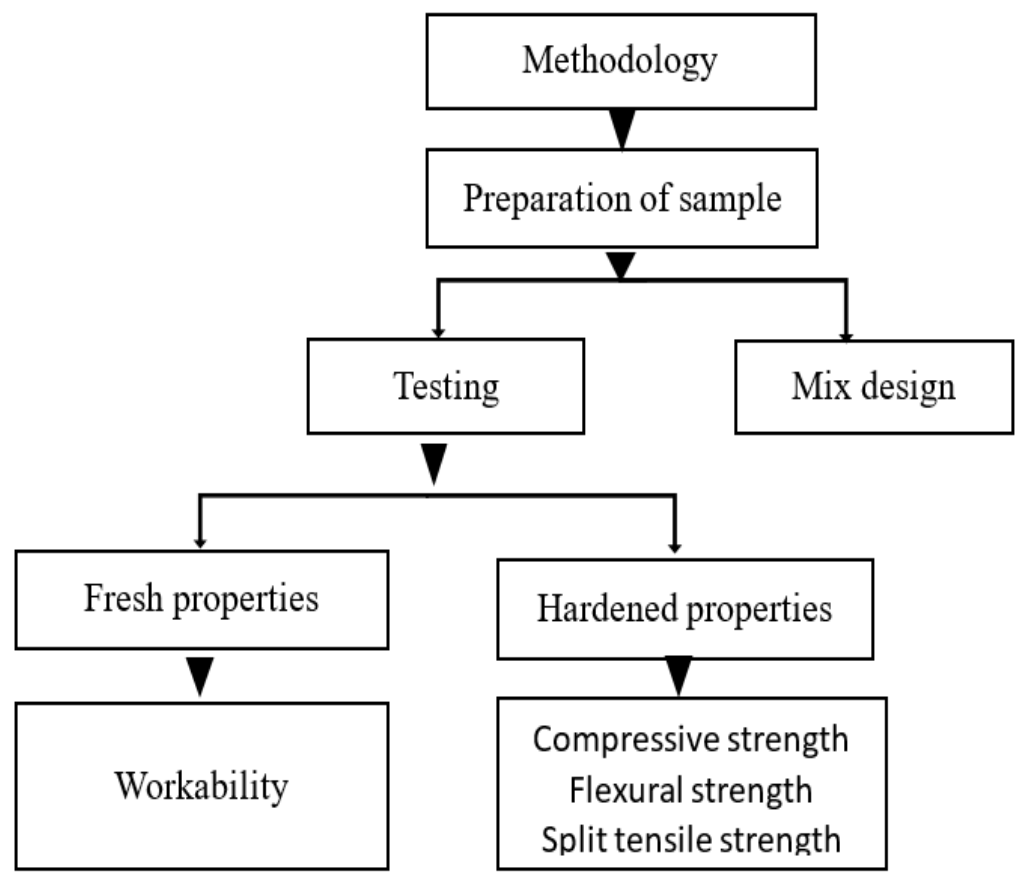

Figure 3: Flow Chart for the Experiment

\section{Concrete Mix Design of Grade M35}

The concrete mix was designed based on the method of the Department of the Environment (DOE) in the United Kingdom. The main aim of concrete mix design was to know the required quantity of each component of concrete which includes; cement, water, aggregate. This would yield concrete with specified properties such as workability, strength, and durability with maximum overall economy [19]. Table 3 shows the detailed mix design of concrete grade M35.

Table 3: Design of Concrete Mix Grade M35

\begin{tabular}{|c|c|c|c|c|}
\hline Stage & \multirow[t]{2}{*}{ Description } & \multicolumn{2}{|c|}{ Value } & \multirow{2}{*}{$\begin{array}{l}\text { Detail } \\
\mathrm{Kg} / \mathrm{m}^{3}\end{array}$} \\
\hline & & MPa & & \\
\hline \multirow{7}{*}{1.} & Curing days & 28 & & \\
\hline & Mean Characteristic Strength & 35 & & \\
\hline & Standard Deviation & 8 & & \\
\hline & Margin: $\mathrm{k}=$ standard deviation $\mathrm{x} 1.64$ for $5 \%$ defective & 13.12 & & $1.64 \times 8=13.12$ \\
\hline & $\begin{array}{l}\text { Target Mean Strength } \\
\text { Characteristic strength }+ \text { margin }\end{array}$ & 48 & & $35+13=48$ \\
\hline & Aggregate Type & & & Crushed \\
\hline & Free Water Cement Ratio & & & 0.48 \\
\hline \multirow{3}{*}{2.} & Slump use & & & $30-60 \mathrm{~mm}$ \\
\hline & Size of aggregate & & & $10 \mathrm{~mm}$ \\
\hline & Water Content & & 230 & \\
\hline 3 & Cement content & & 480 & \\
\hline \multirow[t]{3}{*}{4} & Relative density assume & & & 2.7 \\
\hline & Concrete density & & 2370 & \\
\hline & Total Aggregate Content & & 1660 & \\
\hline
\end{tabular}




\begin{tabular}{|c|l|c|c|c|}
\hline & $2370-230-480$ & & & \\
\hline & & & & $70 \%$ \\
\hline 5 & Percentage passing $600 \mu \mathrm{m}$ sieve & & & $37 \%$ \\
\hline & Proportion of Fine Aggregate & & 615 & $1660 \times 0.37$ \\
\hline & Fine Aggregate Content & & 1045 & $1660-615$ \\
\hline & Coarse aggregate content
\end{tabular}

\section{Mix Proportion}

Table 4 displayed quantity of materials used for the experiment

Table 4: Volume of Mix Proportion

\begin{tabular}{|l|c|c|c|c|c|}
\hline \multicolumn{1}{|c|}{$\begin{array}{c}\text { Quantities } \\
(\mathbf{m 3})\end{array}$} & Steel Fibre (\%) & $\begin{array}{c}\text { Cement } \\
(\mathbf{k g} / \mathbf{m 3})\end{array}$ & Fine Aggregate (kg/m3) & $\begin{array}{c}\text { Coarse Aggregate } \\
(\mathbf{k g} / \mathbf{m 3})\end{array}$ & $\begin{array}{c}\text { Water } \\
(\mathbf{k g} / \mathbf{m 3})\end{array}$ \\
\hline$(1 \mathrm{~m})$ & & 480 & 615 & 1045 & 230 \\
\hline \multirow{2}{*}{\begin{tabular}{c}
$(0.001)$ \\
\multirow{2}{*}{ Prism $(0.00157)$}
\end{tabular}} & 0.0 & 0.480 & 0.620 & 1.045 & 0.230 \\
\cline { 2 - 6 } & 1.0 & 0.480 & 0.620 & 1.045 & 0.230 \\
\hline \multirow{2}{*}{ Cylinder $(0.005)$} & 0.0 & 0.754 & 0.966 & 1.641 & 0.361 \\
\cline { 2 - 6 } & 1.0 & 0.754 & 0.966 & 1.641 & 0.361 \\
\cline { 2 - 6 } & 0.0 & 2.400 & 3.100 & 5.230 & 1.150 \\
\hline
\end{tabular}

\subsection{Methods}

The fresh property of concrete, which is workability is measured using the slump test following ASTM C143/143M [20]. The cube strength of concrete was measured using Uniaxial Compressive Testing Machine which conformed to BS EN 12390-3 [21]. This was done to different specimens cured for 7, 14 and 28 days. The tensile strength was measured after placing the sample on the Universal Testing Machine (UTM). The load and deflection were recorded up to failure. This was done to all specimens in accordance with ASTM C496/ C496M [22]. The flexural strength test of a cylindrical specimen was tested following the ASTM standard [23] for 7, 14 and 28 days.

\section{RESULTS AND DISCUSSIONS}

\section{Workability}

The workability of concrete was evaluated through a slump test method. The result was presented in Figure 4.

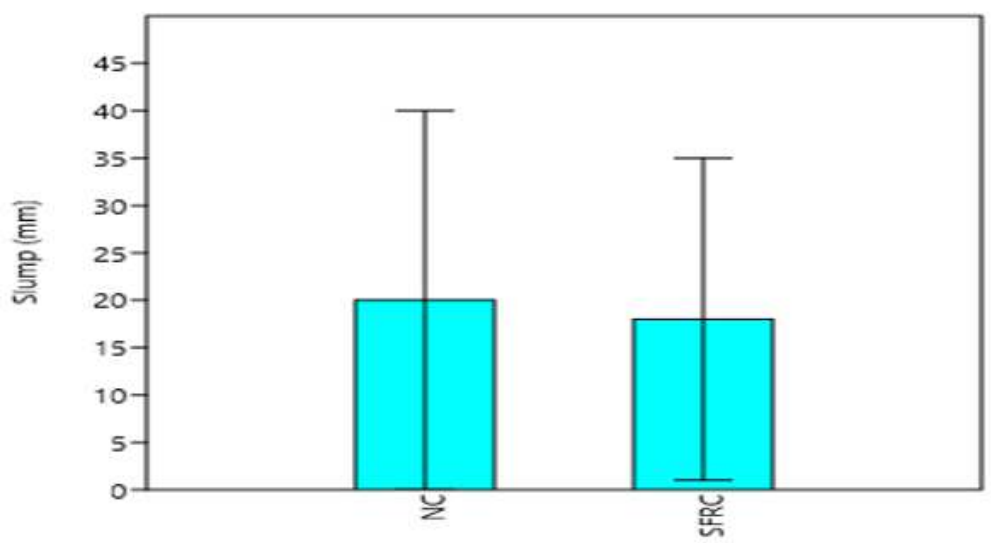

Figure 4: Slump Values of Steel Fibre Reinforced Concrete (SFRC) and Normal Concrete (NC) 
According to findings, the Normal Concrete (NC) has a higher slump value of $40 \mathrm{~mm}$ compared to concrete containing steel fiber which has $35 \mathrm{~mm}$. The result reveals that there was a slight decrease in the slump value of SFRC as a result of the bridging effect of fibers [24]. Based on many researchers, the optimum percentage of steel fiber to be incorporated in concrete is $1 \%$ [25] [26] [27] and [19].

\subsubsection{Compressive Strength of Concrete Containing Steel Fibre}

The compressive strength properties of Steel Fiber Reinforced Concrete (SFRC) is greater than the normal concrete, this could be as a result of continuity of the hydration process [28]. This indicates that the compressive strength of steel fiber reinforced concrete slightly increases due to the bridging effect of fibers [7] and [29]. There was an improvement in the strength of about $14 \%$ when compared to normal concrete. It is in line with the studies of Afroughsabet et al. [30]. Their result indicates an improvement of $2-20 \%$ on the compressive strength compared to normal concrete.

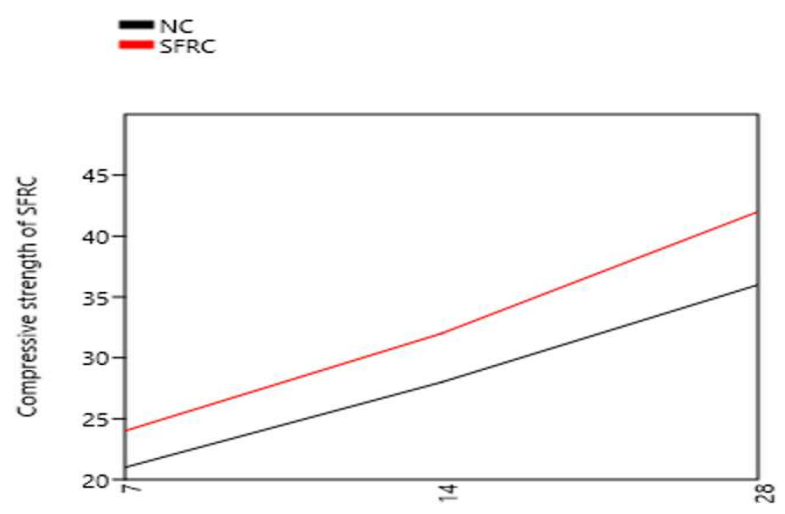

Figure 5: Compressive Strength of SFRC and NC

\subsubsection{Split Tensile Strength of Concrete Containing Steel}

The test results indicate that the incorporation of Steel Fiber (SF) in concrete presented a good improvement in the properties of concrete. It also shows that the split tensile strength of steel fiber reinforced concrete at 7 days is about $11 \%$ higher than the sample with no steel fiber. The strength that was recorded at 14 days is almost the same as that in 7 days which is $12 \%$ higher than the normal concrete. The splitting tensile strength of the cylindrical sample at 28 days displays an increase in strength of $30 \%$ higher than the normal concrete. This is a result of delayed propagation of micro-cracks that considerably improve the tensile strength of the concrete as stated by Gence et al. [31] and reported by Mo et al.[32]. Figure 2 shows the split tensile strength of SFRC. 


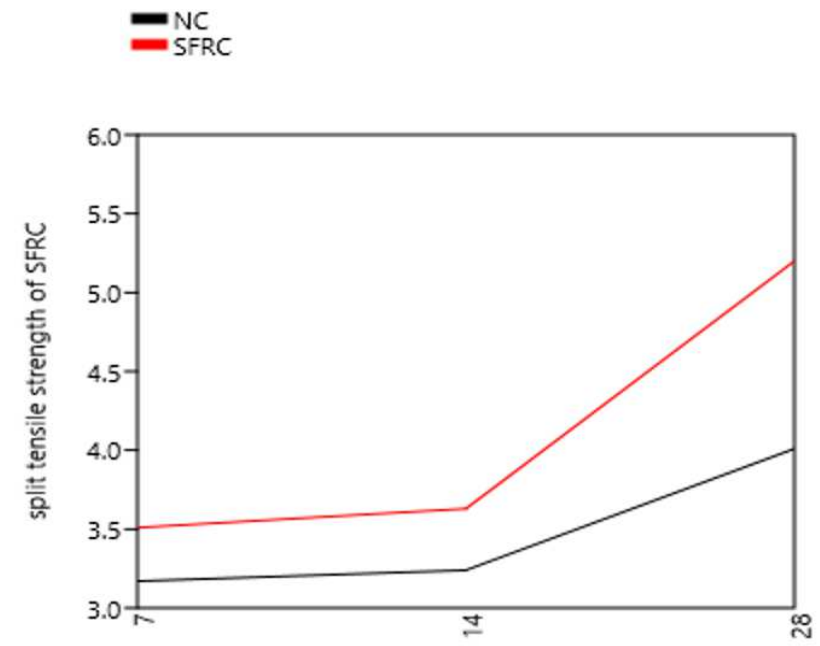

Figure 6: Tensile Strength of SFRC and NC

\subsubsection{Flexural Strength of Concrete Containing Steel Fibre}

Based on this study, it was discovered that there was a good development in the flexural strength of concrete when fiber was added to the concrete. Figure 7 shows the flexural strength of concrete containing steel fiber compares with the normal concrete. The study of Abbass et al. [8] and Malhotra and Chand [33] findings also show a similar trend.

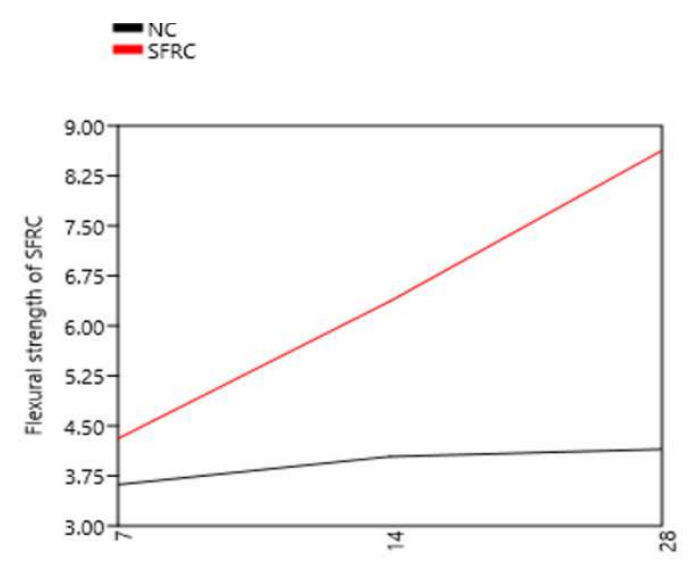

Figure 7: The Flexural Strength of SFRC and NC

The graphical representation of the ultimate flexural strength of the samples at different curing days is shown in Figure 3. From the graph, it can be observed that there was a positive correlation between an increase in flexural strength and the concrete age. This could be a result of improved bonding between steel fiber and concrete matrix as a result of an increase in the development of calcium silica hydrate. The study conforms to Tai et al. [34] findings. It is clear that the normal concrete was unable to withstand a heavy load before it fails. Observing the sample with SF the flexural strength is higher in all cases. Based on this finding, it is clear that a 7 day flexural strength of SFRC is accompanied by a 19\% increment in strength than the normal concrete, this indicates that SFRC has improved flexural strength and can resist load more than the normal concrete [35]. At 14 days the flexural strength increment was 58\% in SFRC against that of normal concrete. Also, the result obtained on 28 days indicate that the flexural strength of SFRC was also improved with about 108\% increment compared to normal concrete which concurred with the studies of Abbass et al. [8], their study shows that the flexural strength of SFRC was above $100 \%$, this means that the brittle nature of normal concrete was transformed to ductile behavior. Generally, in this study, it has been observed that the sample with SF has a greater effect on the flexural 
strength compared to the compressive strength [36].

\section{CONCLUSIONS}

The literature is almost unanimous on the importance of understanding methods for improved flexural strength in concrete materials. According to the studies, the following remarks are established:

- The workability of concrete is not much affected when SF is used, though, a slight reduction in the slump value was observed.

- The SFRC has a greater effect on flexural strength, which recorded above $100 \%$ higher than the NC at 28 days.

- The compressive strength and splitting tensile strength are only slightly affected with values ranging from $0 \%$ $15 \%$ and $30 \%$ increment at 28 days, respectively.

Therefore, the study concludes that the use of steel fiber in concrete can significantly improve the mechanical properties of normal concrete.

\section{ACKNOWLEDGMENTS}

The study was supported by the Tertiary Education Trust Fund (Tet Fund). Sincere thanks to all anonymous contributors.

\section{Conflict of Interest}

No conflict of interest on the side of the authors.

\section{REFERENCES}

1. N. Tabassum, 'a Study on the Compressive \& Flexural Strength Behavior of Steel Fiber Reinforced Concrete Beam.', Int. J. Adv. Res., vol. 6, no. 8, pp. 557-567, 2018.

2. C. Ding, C. Wu, Z. Meng, and G. Fang, 'Mechanical properties and characteristic analysis of the new concave-convex polypropylene macro fiber', J. Eng. Fiber. Fabr., vol. 14, no. 4800, pp. 1-7, 2019.

3. A. Sukumar and E. John, 'Fiber Addition and Its Effect on Concrete Strength', Int. J. Innov. Res. Adv. Eng., vol. 1, no. 8, pp. 144-149, 2014.

4. T. Gehlot, D. Seervi, and P. Chowdhary, 'Study of the Compressive Strength Behaviour of Steel Fibre Reinforced Concrete Using Various Percentage of Steel Fibre', Int. J. Eng. Sci. Invent., vol. 6, no. 8, pp. 41-47, 2017.

5. A. Rana, 'Studies on Steel Fiber Reinforced Concrete', Int. J. Emerg. Technol. Adv. Eng., vol. 3, no. 1, January 2013, pp. 120$127,2013$.

6. N. Venkat Rao, B. Suresh, and K. Arun Kumar, 'Evaluation of mechanical properties of steel fibre reinforced concrete with OPC43 and 53 grades', Int. J. Mech. Prod. Eng. Res. Dev., vol. 8, no. 2, pp. 221-228, 2018.

7. A. Ryabchikov, V. Tamme, and M. Laurson, 'Investigation of mechanical properties of steel fibre-reinforced concrete', IOP Conf. Ser. Mater. Sci. Eng., vol. 96, no. 1, pp. 1-6, 2015.

8. W. Abbass, M. I. Khan, and S. Mourad, 'Evaluation of mechanical properties of steel fiber reinforced concrete with different strengths of concrete', Constr. Build. Mater., vol. 168, no. 21, Febuary 2018, pp. 556-569, 2018.

9. J. Han, M. Zhao, J. Chen, and X. Lan, 'Effects of steel fiber length and coarse aggregate maximum size on mechanical properties of steel fiber reinforced concrete', Constr. Build. Mater., vol. 209, no. 18, March 2019, pp. 577-591, 2019. 
10. M. A. Ulas, K. E. Alyamac, and Z. C. Ulucan, 'Effects of aggregate grading on the properties of steel fibre-reinforced concrete', IOP Conf. Ser. Mater. Sci. Eng., vol. 246, no. 1, pp. 1-10, 2017.

11. R. Srinivasa, M. R. Rama, and P. Jagadees, 'Experimental evaluation of strength properties of steel fibre reinforced concrete', Asian J. Civ. Eng., vol. 17, no. 4, pp. 487-494, 2016.

12. S. M. S. M. K. Samarakoon, P. Ruben, J. Wie, and L. Evangelista, 'Mechanical performance of concrete made of steel fi bers from tire waste', Case Stud. Constr. Mater., vol. 11, no. 7, June 2019, pp. 1-9, 2019.

13. D. Yoo, S. Kim, J. Kim, and B. Chun, 'An experimental study on pullout and tensile behavior of ultra-high-performance concrete reinforced with various steel fibers', Constr. Build. Mater., vol. 206, pp. 46-61, 2019.

14. L. Xu, F. Wu, Y. Chi, P. Cheng, Y. Zeng, and Q. Chen, 'Effects of coarse aggregate and steel fibre contents on mechanical properties of high performance concrete', Constr. Build. Mater., vol. 206, pp. 97-110, 2019.

15. L. Jin, R. Zhang, Y. Tian, G. Dou, and X. Du, 'Experimental investigation on static and dynamic mechanical properties of steel fiber reinforced ultra-high-strength concretes', Constr. Build. Mater., vol. 178, pp. 102-111, 2018.

16. D. Y. Yoo, Y. S. Yoon, and N. Banthia, 'Predicting the post-cracking behavior of normal- and high-strength steel-fiberreinforced concrete beams', Constr. Build. Mater., vol. 93, pp. 477-485, 2015.

17. M. Gajjar, S. Reddy, P. G. Student, and S. Engineering, 'Mechanical properties of steel fibre reinforced concrete in high strength concrete', Int. J. Adv. Eng. Res., vol. 5, no. 04, April 2018, pp. 1400-1409, 2018.

18. C. Pendyala and B. D., 'Experimental Study on Compressive Strength of Concrete by using Different Fibres at various Replacement Levels', -International J. Innov. Res. Sci. Technol., vol. 3, no. 05, October 2016, pp. 18-25, 2016.

19. A. Sadanandam, 'Concrete Mix Design Type and Advantage', the constructor. 2016.

20. ASTM C143/143M-15a, 'Standard Test Method for Slump of Hydraulic-Cement Concrete', Am. Soc. Test. Mater., 2015.

21. BS EN 12390-3, 'Testing hardened concrete - Part 3: Compressive strength of test specimens', Stand. by Br. -Adopted Eur. stanadad, 2009.

22. ASTM C496/ C496M, 'Standard Test Method for Splitting Tensile Strength of Cylindrical Concrete', Am. Soc. Test. Mater., pp. 1-5, 2017.

23. ASTM C78/C78M-18, 'Standard Test Method for Flexural Strength of Concrete (Using Simple Beam with Third-Point Loading)', Am. Soc. Test. Mater., pp. 1-3, 2018.

24. G. Velayutham and C. B. Cheah, 'The effects of steel fibre on the mechanical strength and durability of steel fibre reinforced high strength concrete (SFRHSC) subjected to normal and hygrothermal curing', in MATEC Web of Conferences, 2014, vol. 10, no. March 2014.

25. D. Sinha and A. Verma, 'Investigation on the Effect of Varying Dosages of Steel Fibre on the Strength and Workability Properties Of High Strength Concrete', in International Conference on Re-search and Innovations in Science, Engineering \&Technolog, 2018, vol. 1, pp. 352-346.

26. S. Akramuddin Subhash and K. Shivkumar Nagure, 'Studies on Strength Properties of Steel Fiber Reinforced Concrete with Varied Percentage of Fibre Content', IJIRST-International J. Innov. Res. Sci. Technol., vol. 1, no. 12, pp. 170-174, 2015.

27. B. K. Rao, 'Steel Fiber Reinforced Self-Compacting Concrete Incorporating Class F Fly Ash', Int. J. Eng. Sci. Technol., vol. 2, no. 9, pp. 4936-4943, 2010. 
28. D. Y. Yoo and N. Banthia, 'Mechanical properties of ultra-high-performance fiber-reinforced concrete: A review', Cem. Concr. Compos., vol. 73, pp. 267-280, 2016.

29. S. C. Lee, J. H. Oh, and J. Y. Cho, 'Compressive behavior of fiber-reinforced concrete with end-hooked steel fibers', Materials (Basel)., vol. 8, no. 4, pp. 1442-1458, 2015.

30. V. Afroughsabet, L. Biolzi, and S. Cattaneo, 'Evaluation of Engineering Properties of Calcium Sulfoaluminate Cement-based Concretes Reinforced with Different Types of Fibers', MDPI, vol. 12, no. 4, jULY 2019, pp. 1-18, 2019.

31. O. Gencel, W. Brostow, T. Datashvili, and M. Thedford, 'Workability and mechanical performance of steel fiber-reinforced self-compacting concrete with fly ash', Compos. Interfaces, vol. 18, no. 2, pp. 169-184, 2011.

32. K. H. Mo, K. K. Q. Yap, U. J. Alengaram, and M. Z. Jumaat, 'The effect of steel fibres on the enhancement of flexural and compressive toughness and fracture characteristics of oil palm shell concrete', Constr. Build. Mater., vol. 55, pp. 20-28, 2014.

33. S. Malhotra and J. Chand, 'Experimental investigation on high strength concrete with the addition of steel fiber', Int. J. Civ. Eng. Technol., vol. 8, no. 7, pp. 1130-1140, 2017.

34. Y. S. Tai, S. El-Tawil, and T. H. Chung, 'Performance of deformed steel fibers embedded in ultra-high performance concrete subjected to various pullout rates', Cem. Concr. Res., vol. 89, pp. 1-13, 2016.

35. L. Sun et al., 'Combined effect of steel fibres and steel rebars on impact resistance of high performance concrete', Huagong Xuebao/CIESC J., vol. 60, no. 18, pp. 1677-1684, 2011.

36. D. A. Johnson, N. Pedersen, and C. B. Jacobsen, 'Effect of steel fibers on flexural behaviour of normal and high strength concrete', Int. J. Civ. Environ. Eng., vol. 8, no. 1, pp. 22-26, 2014.

37. T. Sai Kiran, " Comparision of Split Tensile Strength and Flexural of Glass Fiber Reinforced Concrete with Conventional Concrete ", International Journal of Civil, Structural, Environmental and Infrastructure Engineering Research and Development (IJCSEIERD), Vol. 6, Issue 2, pp. 35-42

38. N. Venkat Rao, B. Suresh \& K. Arun Kumar, "Evaluation of Mechanical Properties of Steel Fibre Reinforced Concrete with OPC43 and 53 Grades ", International Journal of Mechanical and Production Engineering Research and Development (IJMPERD), Vol. 8, Issue 2, pp.221-228

39. Sarah Anil \& Nivin Philip, "Influence of Steel Fibers on the Properties of Concrete: A Review”, International Journal of Civil Engineering (IJCE), Vol. 5, Issue 6, pp. 17-24

40. Jyoti Narwal \& Sahil Goel, "Study of Mechanical Properties of Concrete Using Synthetic and Steel Fiber", International Journal of Civil Engineering (IJCE), Vol. 6, Issue 1, pp. 37-44 